\title{
Low-temperature pyrolysis of oily sludge: roles of Fe/AI-pillared bentonites
}

\author{
Hanzhong Jia' ${ }^{1}$, Song Zhao' ${ }^{1}$, Xiehong Zhou' ${ }^{1}$, Chengtun $\mathrm{Qu}^{2}$, Daidi Fan³ ${ }^{3}$ Chuanyi Wang ${ }^{1}$ \\ ${ }^{1}$ Laboratory of Environmental Sciences and Technology, \\ Xinjiang Technical Institute of Physics \& Chemistry, Chinese Academy of Sciences, China \\ ${ }^{2}$ School of Chemical Engineering, Northwest University, China \\ ${ }^{3}$ School of Chemistry and Chemical Engineering, Xi'an Shiyou University, China \\ ${ }^{*}$ Corresponding author's e-mail: jiahz@ms.xjb.ac.cn
}

Keywords: pyrolysis, oily sludge, Fe/Al pillared bentonites, aliphatic hydrocarbons, Lewis acidity.

\begin{abstract}
Pyrolysis is potentially an effective treatment of oily sludge for oil recovery, and the addition of a catalyst is expected to affect its pyrolysis behavior. In the present study, Fe/Al-pillared bentonite with various $\mathrm{Fe} / \mathrm{Al}$ ratios as pyrolysis catalyst is prepared and characterized by $\mathrm{XRD}, \mathrm{N}_{2}$ adsorption, and $\mathrm{NH}_{3}-\mathrm{TPD}$. The integration of $\mathrm{Al}$ and $\mathrm{Fe}$ in the bentonite interlayers to form pillared clay is evidenced by increase in the basal spacing. As a result, a critical ratio of $\mathrm{Fe} / \mathrm{Al}$ exists in the $\mathrm{Fe} / \mathrm{Al}$-pillared bentonite catalytic pyrolysis for oil recovery from the sludge. The oil yield increases with respect to increase in Fe/Al ratio of catalysts, then decreases with further increasing of $\mathrm{Fe} / \mathrm{Al}$ ratio. The optimum oil yield using $2.0 \mathrm{wt} \%$ of $\mathrm{Fe} / \mathrm{Al} 0.5$-pillared bentonite as catalyst attains to $52.46 \%$ compared to $29.23 \%$ without catalyst addition in the present study. In addition, the addition of Fe/Al-pillared bentonite catalyst also improves the quality of pyrolysis-produced oil and promotes the formation of $\mathrm{CH}_{4}$. Fe/Al-pillared bentonite provides acid center in the inner surface, which is beneficial to the cracking reaction of oil molecules in pyrolysis process. The present work implies that Fe/Al-pillared bentonite as addictive holds great potential in industrial pyrolysis of oily sludge.
\end{abstract}

\section{Introduction}

The oily sludge, accumulated from petroleum exploitation and refining processes, is a complex mixture containing different quantities of waste crude oil, wastewater, sand, and mineral particles (Baik 2002, Fakhru'l-Razi 2009). The oily sludge, especially generated during the petroleum refining process, such as oil storage tank sludge, has received increasing attention since it contains a high concentration of petroleum hydrocarbons (PHCs) and other recalcitrant components, most of which are toxic, mutagenic, and carcinogenic (Mater 2006). To achieve effective remediation of oily sludge, a variety of oily sludge treatment methods have been developed, such as land-farming, incineration, solidification/stabilization, solvent extraction, ultrasonic treatment, pyrolysis, photocatalysis, chemical treatment, and biodegradation (Liu 2009, Kök 1998, Beis et al. 2002, Ciajolo 1984, Saha et al. 2006, Li et al. 1995, Ubani et al. 2016). Among those treatment technologies, the conversion of oily sludge into various useful materials, such as lower molecular weight organic compounds and carbonaceous residue, not only solves the disposal problem but also matches the appeal of resource utilization (Pánek et al. 2014). Thus, thermal disposal approaches such as pyrolysis to convert this stored energy into a usable energy source have been developed for heating or perhaps as a liquid fuel substitute.
With its unique characteristics to break down large molecules into smaller ones, pyrolysis has been proven to be an alternative for the disposal of many wastes such as plastic waste, biomass, municipal solid waste, and other solid wastes (Liu et al. 2009, Kök et al. 1998, Beis et al. 2002, Ciajolo et al. 1984, Wiśniewski et al. 2015). Such treatment not only minimizes or disposes the volume of solid waste but also yields valuable products, such as gaseous, liquid and solid products. During the pyrolysis process, operation conditions, such as temperature, pressure, heating rate, residence time, and reactor design, are crucial to pyrolysis products (Albright et al. 1983, wang et al. 2007, Shen et al. 2002, Shie et al. 2000). As reported previously, high heating rates benefit gas and liquid yield, and slow heating rate with long vapor residence time might be favorable for char recovery (Kandiyoti et al. 2008). In addition, the type and amount of pyrolysis products are also significantly influenced by the presence of additives with a catalytic effect (Albright et al. 1983). The role of various additives on the enhancement of the pyrolysis of oily sludge was investigated previously (Shie et al. 1999, 2000, 2002, 2003 and 2004). For example, the addition of iron and aluminum salts can improve liquid yield and achieve the improvement of the quality of pyrolysis oil (Kandiyoti et al. 2008, Shie et al. 2000). Also, the addition of those useful additives at optimum reaction conditions has a great potential to affect the cracking process by shortening cracking time, lowering the required temperature 
and reducing the proportion of solid residue (Shie et al. 1999, 2000, 2002, 2003 and 2004).

Bentonite is a kind of layered clay composed mainly of montmorillonite, which can be easily modified by inserting various functional groups into the interlayers to achieve better adsorption and catalysis properties to target contaminants ( $\mathrm{Ge}$ et al. 1994). Bentonite modified by OH-Fe/Al (a bentonite modified with pillaring solution of poly (hydroxo Al(III) or $\mathrm{Fe}(\mathrm{III})$ cations) has been applied in wastewater treatment due to its outstanding adsorption properties, but its catalysis properties in the pyrolysis of oily sludge are still under study. Thus, the objectives of present work are to 1) evaluate the catalysis effect of $\mathrm{OH}-\mathrm{Fe} / \mathrm{Al}$ pillared bentonites on pyrolysis behavior of oily sludge; 2) investigate the optimum $\mathrm{Fe} / \mathrm{Al}$ ratio for oil recovery from the oily sludge; 3 ) explore the influence of pillared bentonite on pyrolysis products; and 4) further gain insight into the mechanism involved in the pyrolysis of oily sludge in the presence of various $\mathrm{OH}-\mathrm{Fe} / \mathrm{Al}$ pillared bentonites. Such knowledge as the role of $\mathrm{OH}-\mathrm{Fe} / \mathrm{Al}$ pillared bentonites in oily sludge pyrolysis and its influence on products is significantly necessary for developing environmentally friendly and economically competitive approaches for oily sludge treatment.

\section{Materials and methods}

\section{Chemicals and materials}

Anhydrous ferric chloride $\left(\mathrm{FeCl}_{3}\right)$, sodium chloride $(\mathrm{NaCl})$, aluminium chloride $\left(\mathrm{AlCl}_{3}\right)$, and sodium hydroxide $(\mathrm{NaOH})$ were obtained from Sinopharm Chemical Reagent Co., Ltd (Shanghai, China). All the chemicals were used as received. Bentonite clay mineral was obtained from Zhejiang Feng-Hong Clay Chemicals Co., Ltd (Zhejiang, China).

The oily sludge used in the present study was collected from the oil separating tank in Xinjiang Branch Company of Petro China, Karamay, China. The oily sludge sample appears black and possesses poor settle-ability. The composition of the oily sludge, including oil, water, and sediment content, was analyzed by the following procedures. To measure oil content, $5 \mathrm{~g}$ of oily sludge was extracted in Soxhlet extractor with petroleum ether for $24 \mathrm{~h}$, and then the oil content in the extract was quantified gravimetrically using UV spectrophotometry. The sediment content was weighed as solid after $12 \mathrm{~h}$-drying at $102^{\circ} \mathrm{C}$. The oily sludge sample contains $60.52 \mathrm{wt} \%$ of moisture, $9.90 \mathrm{wt} \%$ volatile matters, $15.20 \mathrm{wt} \%$ of ash content and $14.38 \mathrm{wt} \%$ of oil content. The sample heating value of $5683 \mathrm{~kJ} \mathrm{~kg}^{-1}$ was measured by employing a bomb calorimeter. The elemental analyses for the extracted oil were conducted on a Perkin Elmer 2400 Series II CHNS/O Analyzer (Norwalk, USA). The main elemental compositions of the exacted oil are C (wt. 82.3\%), H (wt. 14.2\%), N (wt. $0.49 \%$ ), S (wt. 2.1\%), and O (wt. 0.9\%). The composition of the extracted oil was also identified (methods are described in detail below), and the results are listed in Table 1.

\section{Preparation of the pillared bentonite}

The Fe/Al-pillared bentonites were prepared by pillaring the bentonite through cation-exchanging process developed by $\mathrm{Ge}$ et al. (Ge et al. 1994). Briefly, the Fe-pillaring (or Al-pillaring) solution was prepared by slowly adding a $1.0 \mathrm{M} \mathrm{NaOH}$ solution with a rate of $2-3 \mathrm{~mL} \mathrm{~min}-1$ to a $1.0 \mathrm{M} \mathrm{FeCl}_{3}\left(\mathrm{or} \mathrm{AlCl}_{3}\right)$ solution until a molar ratio of $\mathrm{OH}^{-} / \mathrm{Fe}^{3+}=2.0$ was reached. The solution was aged for $24 \mathrm{~h}$ at room temperature for Fe-pillaring and $60^{\circ} \mathrm{C}$ for Al-pillaring solution. To prepare the $\mathrm{Fe} / \mathrm{Al}$-pillaring solutions, an Al-pillaring solution was slowly added to Fe-pillaring solutions, and the $\mathrm{Fe} / \mathrm{Al}$ ratios were adjusted to $0.05,0.1,0.5$, and 1.0. Then, the Fe/Al-pillaring solutions were added to the bentonite suspension (2\%) to obtain $10 \mathrm{mmol}$ $(\mathrm{Fe}+\mathrm{Al}) / \mathrm{g}$ bentonite. After stirring at $60^{\circ} \mathrm{C}$ for $24 \mathrm{~h}$, the aged suspensions were centrifugally washed until chloride ions therein were completely removed. Finally the suspensions were dried in an oven at $60^{\circ} \mathrm{C}$ and calcined at $250^{\circ} \mathrm{C}$ for $3 \mathrm{~h}$. The obtained Fe/Al-pillared bentonites were referred to as $\mathrm{Fe} / \mathrm{Al}$ 0.05-Bent, $\mathrm{Fe} / \mathrm{Al}$ 0.1-Bent, Fe/Al 0.5-Bent, and Fe/Al 1.0 -Bent based on the specific Fe/Al ratios.

\section{Characterization of pillared bentonite}

$\mathrm{X}$-ray diffraction (XRD) patterns for freeze-dried powders of the pillared-clays were recorded to determine $d(001)$ basal spacing. The X-ray diffractometer (Rigaku Rotaflex D/Max$-2200 / \mathrm{PC}$ ) was equipped with a $\mathrm{CuK} \alpha$ radiation source and a crystal graphite monochromater, operating at $45 \mathrm{kV}$ and $100 \mathrm{~mA}$. The XRD signals were collected with diffraction angles ranging from 4 to $50^{\circ}$ at a canning rate of 0.2 degree $\mathrm{min}^{-1}$. The nitrogen adsorption isotherms at $77 \mathrm{~K}$ within $\mathrm{P} / \mathrm{P}^{0}$ values of $10^{-5}$ to 0.999 were obtained using a Quantachrome Autosorp 1C instrument after degassing under vacuum for $3 \mathrm{~h}$ at $180^{\circ} \mathrm{C}$, and the adsorption data were used to determine the textural properties of the samples. For the porosity analysis, the Barrett-JoynerHalenda (BJH) method was used (Bridgwater et al. 1999, Wei et al. 2006). The samples were out-gassed overnight (12 h) under nitrogen prior to adsorption measurement. Pore distributions and pore volume were calculated using the adsorption branch of the $\mathrm{N}_{2}$ isotherms based on the BJH model. Specific surface area was calculated on the basis of the BET equation.

Analysis of chem-BET of prepared catalysts was conducted in a pulsar TPR/TPD (Quantachrome). Firstly, approximately $40 \mathrm{mg}$ of each tested catalyst was placed in a quartz tube. After pre-treating at $500^{\circ} \mathrm{C}$ for $2 \mathrm{~h}$ under a He flow of $40 \mathrm{~mL} \mathrm{~min}^{-1}$, the samples were cooled to $120^{\circ} \mathrm{C}$ and dosed for $30 \mathrm{~min}$ with $8 \% \mathrm{NH}_{3}$ in $\mathrm{He}$ (balance), again at $20 \mathrm{~mL} \mathrm{~min}^{-1}$. The dosing temperature was chosen to prevent physisorption of $\mathrm{NH}_{3}$ on the catalyst surface. The dosing resulted in complete adsorption of $\mathrm{NH}_{3}$ to all available acid sites. After dosing, the samples were cooled to $120^{\circ} \mathrm{C}$ then heated to $800^{\circ} \mathrm{C}$ at $15^{\circ} \mathrm{C} \mathrm{min}-1$ under $\mathrm{He}$ flow of $40 \mathrm{~mL} \mathrm{~min}{ }^{-1}$. An $\mathrm{NH}_{3}$ adsorption-temperature curve was obtained by recording the peaks of the spectra.

\section{Pyrolysis of oily sludge}

The pyrolysis experiments of the oily sludge were carried out in a horizontal quartz reactor, which was placed in an electrical furnace. As shown in Fig. 1, the pyrolysis apparatus comprises of furnace, quartz reactor, temperature controller, liquid collective units, gaseous sampling bag, float ball gas flow meter, and $\mathrm{N}_{2}$ gas cylinder. In the pyrolysis process, $150 \mathrm{~g}$ of oily sludge was loaded in the reactor. Then, a $\mathrm{N}_{2}$ flow of $200 \mathrm{~mL} \mathrm{~min}^{-1}$ was passed through the reactor for $10 \mathrm{~min}$ prior to the reaction to maintain an inert atmosphere. After that the $\mathrm{N}_{2}$ flow was reduced to $100 \mathrm{~mL} \mathrm{~min}^{-1}$ during the pyrolytic experiment. Accurate measurement of reaction temperature was controlled and monitored by an intellectualized program-rising temperature instrument and temperature controller. The reactor was heated at a rate of $10 \mathrm{~K} \mathrm{~min}^{-1}$ up to $723 \mathrm{~K}$, and 
Table 1. Composition (GC-MS peak area, \%) of originally extracted oil and pyrolysis oil in the presence and absence of catalyst

\begin{tabular}{|c|c|c|c|}
\hline \multirow[b]{2}{*}{ Pyrolysis products } & \multicolumn{3}{|c|}{ GC-MS peak area (\%) } \\
\hline & $\begin{array}{l}\text { Originally } \\
\text { extracted oil }\end{array}$ & $\begin{array}{c}\text { Pyrolysis oil } \\
\text { without catalyst }\end{array}$ & $\begin{array}{l}\text { Pyrolysis oil } \\
\text { with catalyst }\end{array}$ \\
\hline 1-Ethyl-2,2,6-trimethylcyclohexane & 0.35 & 0.62 & 0.33 \\
\hline 2-methyl-Decane & 2.43 & 2.10 & 0.21 \\
\hline 4-methyl-Decane & 0.43 & 0.93 & - \\
\hline Undecane & 1.02 & 0.97 & 1.03 \\
\hline 2-methyl-trans-Decalin & - & - & 0.18 \\
\hline 4,6-dimethyl-Undecane & 2.91 & 3.45 & - \\
\hline Dodecane & 1.84 & 1.38 & 1.41 \\
\hline 2,6-dimethyl-Undecane & 2.04 & 1.88 & 1.61 \\
\hline 2-methyl-Dodecane & 3.25 & 3.07 & 0.30 \\
\hline Tridecane & 0.57 & 1.33 & 1.67 \\
\hline 2,6,10-trimethyl-Dodecane & 1.84 & 1.97 & 1.51 \\
\hline Tetradecane & 1.04 & 1.42 & 1.72 \\
\hline Cyclotetradecane & 1.21 & 1.04 & 2.31 \\
\hline Hexadecane & 2.05 & 2.17 & 4.87 \\
\hline Pentadecane & 1.54 & 1.69 & 2.23 \\
\hline 1,6,7-trimethyl-Naphthalene & - & - & 0.32 \\
\hline 1,4,6-trimethyl-Naphthalene & - & - & 0.36 \\
\hline 2-methyl- Pentadecane & 0.12 & - & 0.38 \\
\hline 1-Hexadecene & - & - & 0.51 \\
\hline 2,6,10-trimethyl-Pentadecane & 3.44 & 3.42 & 2.89 \\
\hline 1-Octadecene & - & - & 0.67 \\
\hline 2-methyl-Hexadecane & - & - & 0.21 \\
\hline Heptadecane & 2.43 & 2.81 & 2.56 \\
\hline 2,6,10,14-tetramethyl-Pentadecane & 3.83 & 4.33 & 4.01 \\
\hline 2-methyl-Heptadecane & 0.13 & - & 0.69 \\
\hline Octadecane & 2.53 & 2.44 & 2.22 \\
\hline 2,6,10,14-tetramethyl- Hexadecane & 4.46 & 4.58 & 4.48 \\
\hline 1-Eicosene & - & - & 0.74 \\
\hline 2-methyl-Octadecane & - & - & 0.32 \\
\hline Heneicosane & 2.19 & 2.26 & 1.04 \\
\hline Nonadecane & 2.91 & 2.88 & 2.32 \\
\hline 2-methyl-Nonadecane & 0.05 & - & 0.12 \\
\hline 1-Nonadecene & - & - & 0.21 \\
\hline Eicosane & 7.02 & 7.07 & 3.03 \\
\hline Heneicosane & 3.46 & 3.43 & 1.99 \\
\hline 3-methyl-Heneicosane & - & - & 0.19 \\
\hline Docosane & 2.43 & 2.60 & 1.98 \\
\hline Tricosane & 3.21 & 2.98 & 2.02 \\
\hline Tetracosane & 21.52 & 19.50 & 9.99 \\
\hline Pentacosane & 2.39 & 2.31 & 1.66 \\
\hline Hexacosane & 2.06 & 2.02 & 1.74 \\
\hline Heptacosane & 1.98 & 1.67 & 0.95 \\
\hline Nonacosane & 4.45 & 3.13 & 0.57 \\
\hline 1-chloro-Heptacosane & 1.52 & 1.38 & 0.35 \\
\hline Hentriacontane & 2.38 & 2.90 & - \\
\hline $\begin{array}{l}\text { 1,1,3,3,5,5,7,7,9,9,11,11,13,13,15,15-hexadcamethyl- } \\
\text {-Octasiloxane }\end{array}$ & 3.24 & 4.37 & - \\
\hline
\end{tabular}


then held for $3 \mathrm{~h}$. The pyrolysis products were swept out of the reactor and passed through a glass condenser immersed in a mixture of ice and water, and condensable liquid fractions were collected. The non-condensable volatiles were collected in vacuum gas bags to analyze the composition. After the reaction, the aqueous phase in the condensate was separated from the organic phase (pyrolysis oil) by centrifugation. The yield of pyrolysis oil can be calculated following the Eq. (1):

$$
\eta=M_{\mathrm{r}} / M_{0}
$$

where $\eta$ is the yield of pyrolysis oil (\%), $M_{0}$ is the oil content in oily sludge samples $(\mathrm{g}) ; \mathrm{M}_{\mathrm{r}}$ is the mass of oil obtained in pyrolysis (g). Gas yields were calculated through the measured volume and mole mass of mixed gaseous products. After the pyrolysis, the solid residue was weighed, and the char yield was calculated by deducting ash content from the total weight of solid residue.

\section{Analysis of oil composition}

The composition of original extracted oil and liquid products was identified using an Agilent 7890A-5975C gas chromatograph incorporated with a mass spectrometer operated on a full scan mode (30-500 amu), where a HP-5MS capillary column (length $=30 \mathrm{~m}$; internal diameter $=250 \mu \mathrm{m}$; film thickness $=0.25 \mu \mathrm{m}$ ) was employed. Helium was used as carrier gas at a flow rate of $1.2 \mathrm{~mL} / \mathrm{min}$ with splitless injection at $230^{\circ} \mathrm{C}$. The oven temperature was programmed from $50^{\circ} \mathrm{C}$ (2 min hold), and then to $300{ }^{\circ} \mathrm{C}\left(10^{\circ} \mathrm{C} \mathrm{min}{ }^{-1}, 10\right.$ min hold $)$.

The product gas was collected periodically into sampling bag and analyzed off-line by an Agilent Technologies 7890A gas chromatograph using an HP5 column $(30 \mathrm{~m} \times 0.25 \mathrm{~mm} \times 0.25 \mu \mathrm{m})$. Hydrogen was used as the carrier gas at a nominal flow rate of $1 \mathrm{ml} / \mathrm{min}$. The oven temperature programming was initiated from temperature $55^{\circ} \mathrm{C}$ without holding time. The total run time was 12 min. Gas products, such as $\mathrm{CO}, \mathrm{CO}_{2}$, and $\mathrm{C}_{\mathrm{x}} \mathrm{H}_{\mathrm{y}}\left(\mathrm{CH}_{4}\right.$, $\mathrm{C}_{2} \mathrm{H}_{4} \mathrm{C}_{2} \mathrm{H}_{6}$, and $\left.\mathrm{C}_{3} \mathrm{H}_{8}\right)$ ), were identified. Calorific value analysis of solid products was performed in Oxygen Bomb Calorimeter (AN2010A) by combustion of certified benzoic acid.

\section{Results and discussion}

\section{Characterization of Fe/Al-pillared bentonite}

The XRD patterns of original bentonite, Fe/Al 0.05-Bent, $\mathrm{Fe} / \mathrm{Al}$ 0.1-Bent, Fe/Al 0.5-Bent, and $\mathrm{Fe} / \mathrm{Al}$ 1.0-Bent are presented in Fig. 2. The basal spacing of clay was calculated using the first-order reflection (001) by the Bragg equation:

$$
\mathrm{d}(001)=1.54178 /(2 \sin (2 \theta / 2))
$$

in which $d(001)$ refers to the basal spacing of clay, and $\theta$ is the incident angle. The basal spacing of original bentonite is $12.1 \AA$. For original bentonite saturated mainly by $\mathrm{Na}^{+}$, the interlayer space is expected to hydrate with a monolayer of water when the relative humidity is in the range of $30-70 \%$, resulting in expanded basal spacing, $\sim 12.5 \AA$ (Berend et al. 1995). After intercalating with $\mathrm{Fe} / \mathrm{Al}$-pillaring, the basal spacings increase to $14.6,15.1,15.4$, and $14.9 \AA$ for $\mathrm{Fe} / \mathrm{Al} 0.05$-Bent, $\mathrm{Fe} / \mathrm{Al}$ 0.1-Bent, $\mathrm{Fe} / \mathrm{Al}$ 0.5-Bent, and Fe/Al 1.0-Bent, respectively, corresponding to an interlayer distance of 5-5.8 $\AA$ assuming one bentonite layer thickness is of $9.6 \AA$. This result indicates that the interlayer environment is successfully modified by $\mathrm{Fe} / \mathrm{Al}$ pillaring. As reported previously, the Fe/Al ratio influences the size of pillaring, and the sample of Fe/Al 0.5-Bent exhibits the highest basal spacing of pillared clay (Chen et al. 2015).

The surface areas of clay minerals, related to the numbers and sizes of internal and external pores, have great influence on its catalysis activity. Nitrogen adsorption-desorption isotherms of original bentonite, Fe/Al 0.05-Bent, Fe/Al 0.1-Bent, Fe/Al 0.5-Bent, and Fe/Al 1.0-Bentare are illustrated in Fig. 3. According to the IUPAC classification or BDDT (Brunauer, Deming, Deming and Teller) classification, the nitrogen adsorption/desorption isotherms of bentonite samples demonstrate Type IV behavior which is characteristic of mesoporous structure (Sing et al. 1958). The textural parameters

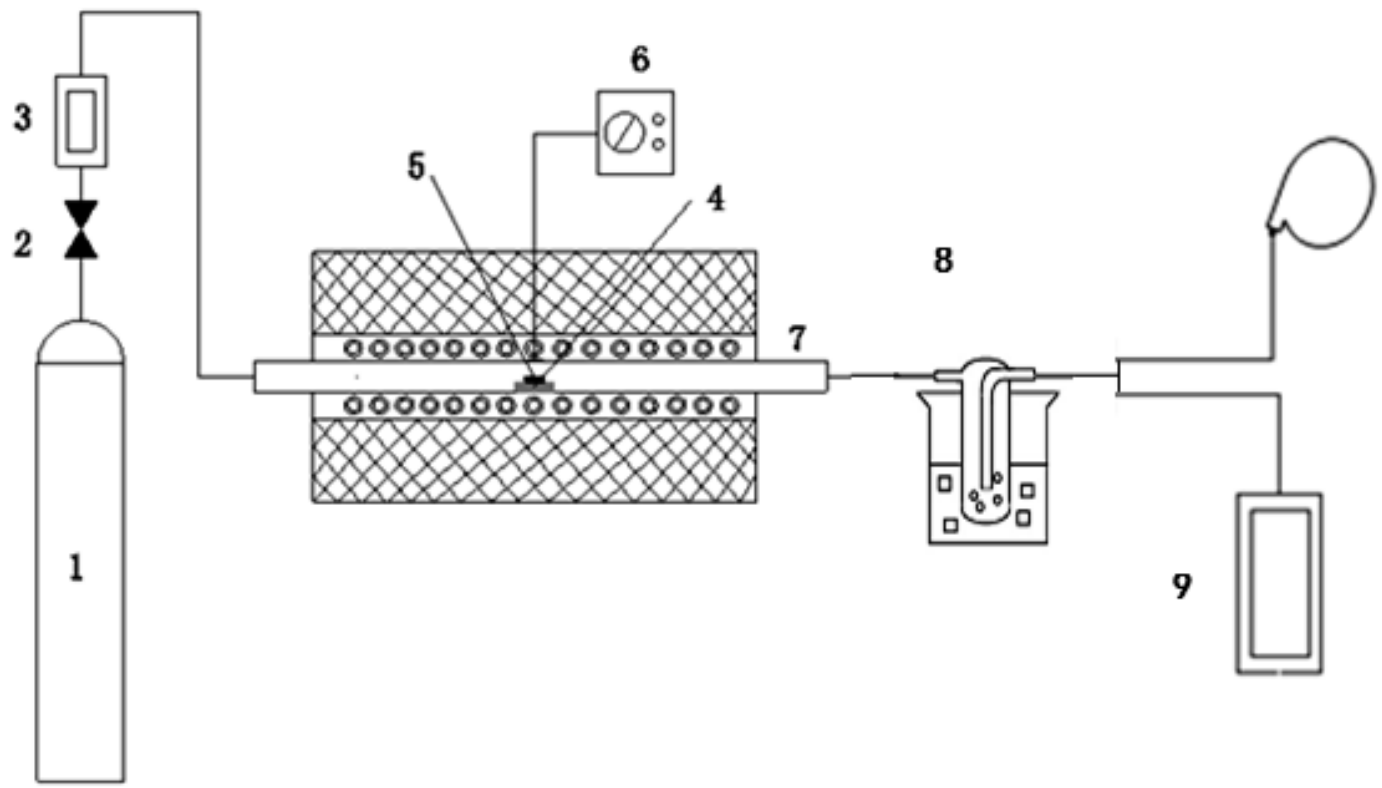

Fig. 1. Experimental system of oil pyrolysis. 1. N2 gas cylinder, 2. Flow regulating valve, 3. Rotameter, 4. quartz reactor, 5. Sample, 6. Temperature controller, 7. Electric furnace, 8. Condensing unit, 9. Liquid collective unit, and gaseous sampling bag 
including specific surface area $\left(\mathrm{S}_{\mathrm{BET}}\right)$, total pore volume $\left(\mathrm{V}_{\mathrm{T}}\right)$ and average pore diameter of original bentonite and $\mathrm{Al} / \mathrm{Fe}$ -pillared-Bent samples are summarized in Table 2. The specific BET surface area of original bentonite is $37.71 \mathrm{~m}^{2} \mathrm{~g}^{-1}$, and the total pore volume is $0.0834 \mathrm{~cm}^{3} \mathrm{~g}^{-1}$. After exchanged with $\mathrm{Fe} / \mathrm{Al}$ pillaring, the specific BET surface area increases to 53.13, 77.06, 93.10, and $117.99 \mathrm{~m}^{2} \mathrm{~g}^{-1}$, and the total pore volume is improved to $0.0868,0.1190,0.1314$, and $0.1295 \mathrm{~cm}^{3}$ $\mathrm{g}^{-1}$ for 0.05-Bent, 0.1-Bent, 0.5-Bent and 1.0-Bent, respectively. The increase in the surface areas of pillared bentonite may be ascribed to the increase of micropores and enlarged cumulative pore volume of micropores. It is noted that the surface area increases with the $\mathrm{Fe} / \mathrm{Al}$ ratio, and the pore volume of $\mathrm{Fe} / \mathrm{Al}$ 0.5 -Bent is the biggest among all the pillared sample clays. In addition, the average pore diameters of Fe/Al 0.1 -Bent and 0.5 -Bent slightly decrease to 5.65 and 5.39 in comparison with original bentonite of $6.59 \mathrm{~nm}$, indicating that bentonites pillared with these inorganic polycations result in a more developed porosity than their counterpart, original bentonite.
The similarity of the mesopore size distributions indicates that the size of the mesopore may depend more on the stacking of the silicate leaves rather than on the interlayer distance.

The solid acidity of clay minerals plays an important role in its catalysis properties. The acidic property of the pillared clays is mainly of Lewis-type, which is usually related to the presence of pillars and to the amount of aluminum incorporated with the oligocations (Tyagi et al. 2006). In the present study, the Lewis acidity (ability of being an electron pair acceptor) was evaluated by $\mathrm{NH}_{3}$-TPD experiments, and the ammonia desorbed vs temperature is developed as shown in Fig. 4. The obtained results show that the pillared clays associated with various $\mathrm{Fe} / \mathrm{Al}$ ratio exhibit different capabilities on the amount of chemisorbed $\mathrm{NH}_{3}$ under different temperatures. Generally, the acidity signal is weak at $150-300^{\circ} \mathrm{C}$, but it is strong in the range of $300-700^{\circ} \mathrm{C}$. The obtained result indicates that the strong acidity has more quantity than weak acidity in the present study. The number of acid sites is higher for the sample of Fe/Al 0.5-Bent than original clay and other pillared bentonites.

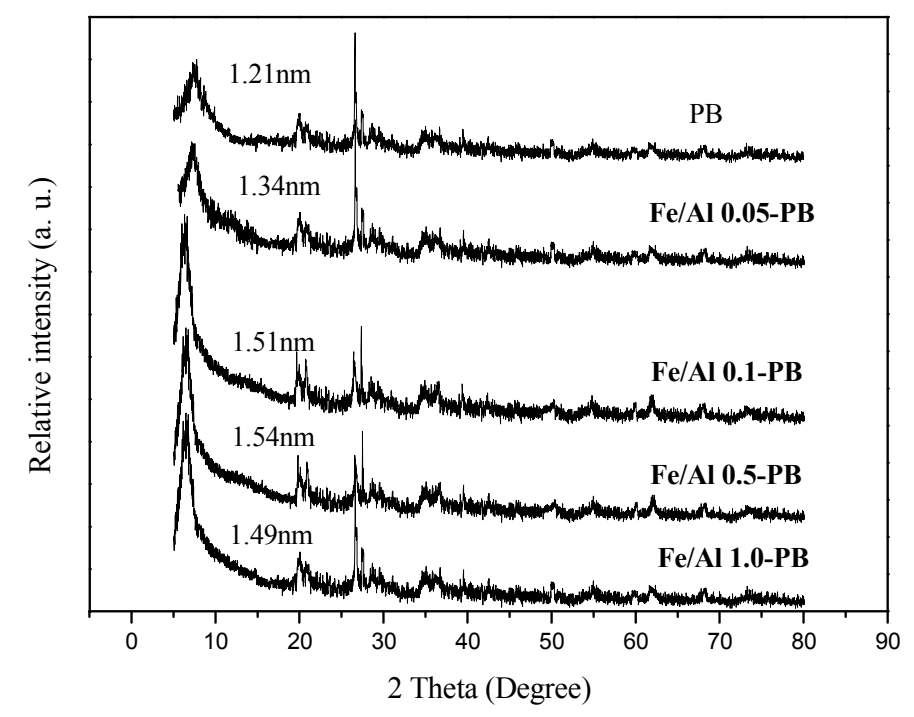

Fig. 2. X-ray diffraction patterns of the synthesized Fe/Al-pillared Bentonite samples

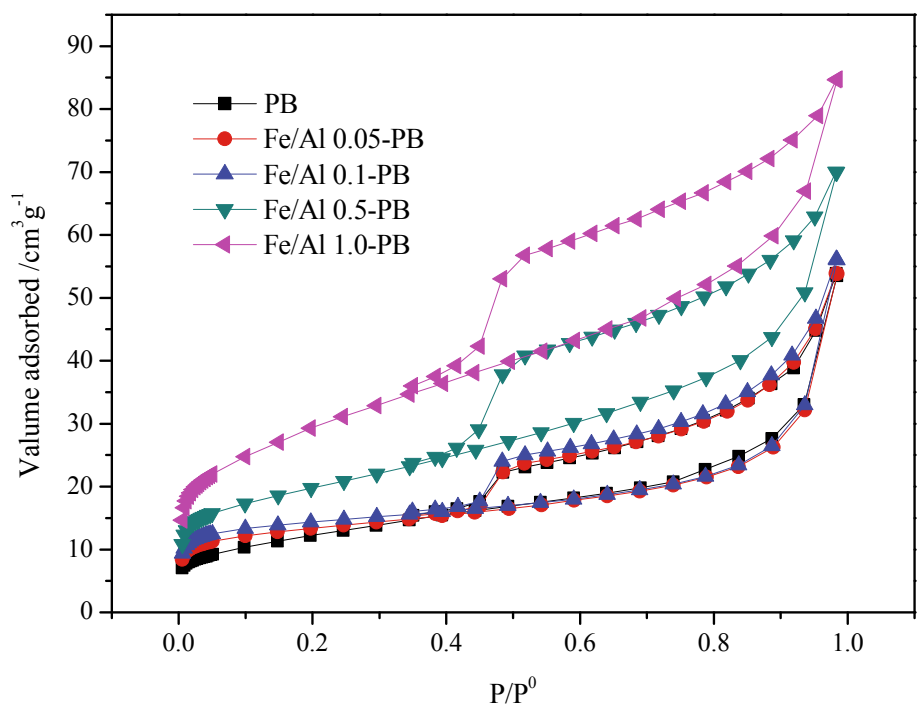

Fig. 3. The N2 adsorption-desorption isotherms of Fe/Al-pillared Bentonite samples at $77 \mathrm{~K}$ 


\section{Pyrolysis of oily sludge catalyzed by Fe/Al-pillared bentonite}

The major product of pyrolysis treatment can be a liquid (i.e. pyrolysis oil), which could be used as a fuel or a source of other valuable chemical products (Liu et al. 2009, Ge et al., 1994). As shown in Fig. 5, the presence of pillared bentonites enhances the oil yield and decreases the yield of char in pyrolysis process of oily sludge. Compared with pyrolysis in the absence of catalyst, the oil yields increase by $7.08 \%, 18.65 \%, 23.23 \%$, and $17.43 \%$ with the addition of $\mathrm{Fe} / \mathrm{Al} 0.05-\mathrm{Bent}, \mathrm{Fe} / \mathrm{Al}$ 0.1-Bent, Fe/Al 0.5-Bent, and Fe/Al 1.0-Bent, respectively. This can be attributed to the fact that the pillared bentonites with $\mathrm{Fe} / \mathrm{Al}$ produce a porous material with a high surface area, which is favorable to contraction and cracking of oil molecules.

Table 2. Characterization parameters of the synthesized Fe/Al pillared bentonite samples

\begin{tabular}{|c|c|c|c|c|}
\hline $\begin{array}{c}\text { Pillared } \\
\text { bentonites }\end{array}$ & $\begin{array}{c}\mathrm{S}_{\mathrm{BET}}^{\mathrm{a}} \\
\left(\mathrm{m}^{2} \mathrm{~g}^{-1}\right)\end{array}$ & $\begin{array}{c}\mathrm{V}_{\mathrm{T}}^{\mathrm{b}} \\
\left(\mathrm{m}^{3} \mathrm{~g}^{-1}\right)\end{array}$ & $\begin{array}{c}\text { Average pore diameter } \\
(\mathrm{nm})\end{array}$ & $\begin{array}{c}\mathrm{d}_{\mathrm{O} 01} \\
(\AA)\end{array}$ \\
\hline PB & 37.71 & 0.0834 & 6.59 & 12.1 \\
\hline Fe/Al 0.05-PB & 53.13 & 0.0868 & 6.91 & 13.4 \\
\hline Fe/AI0.1-PB & 77.06 & 0.1190 & 5.65 & 15.1 \\
\hline Fe/Al0.5-PB & 93.10 & 0.1314 & 5.39 & 15.4 \\
\hline Fe/Al1.0-PB & 117.99 & 0.1295 & 7.29 & 14.9 \\
\hline
\end{tabular}

${ }^{\text {a }} \mathrm{S}_{\mathrm{BET}}=$ total surface area. ${ }^{\mathrm{b}} \mathrm{V}_{\mathrm{T}}=$ total pore volume.

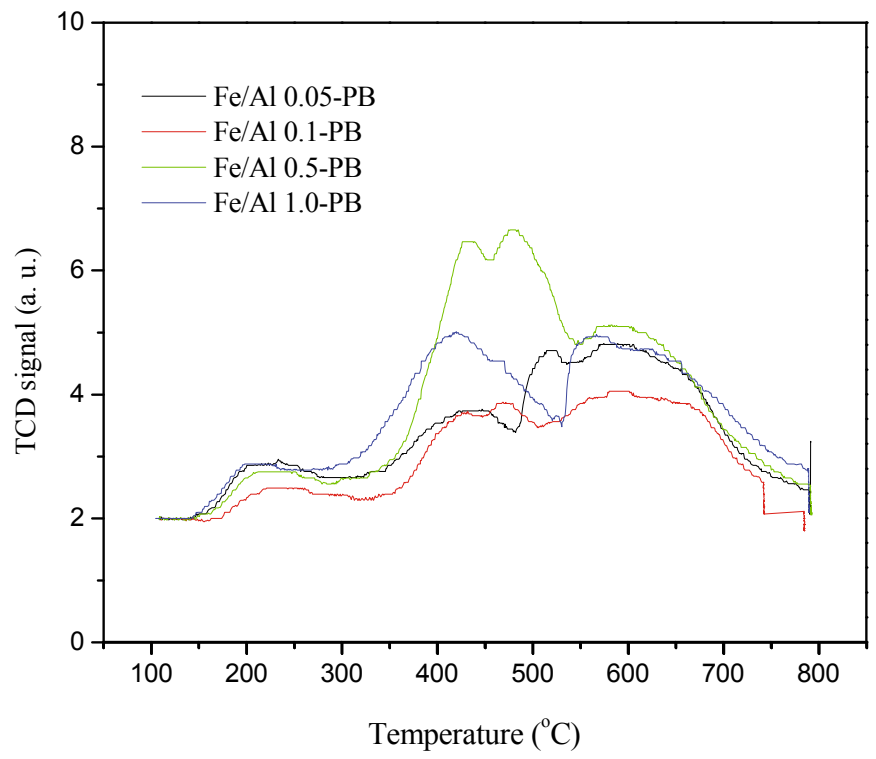

Fig. 4. NH3-TPD spectra of various ratios of Fe/Al-pillared bentonites

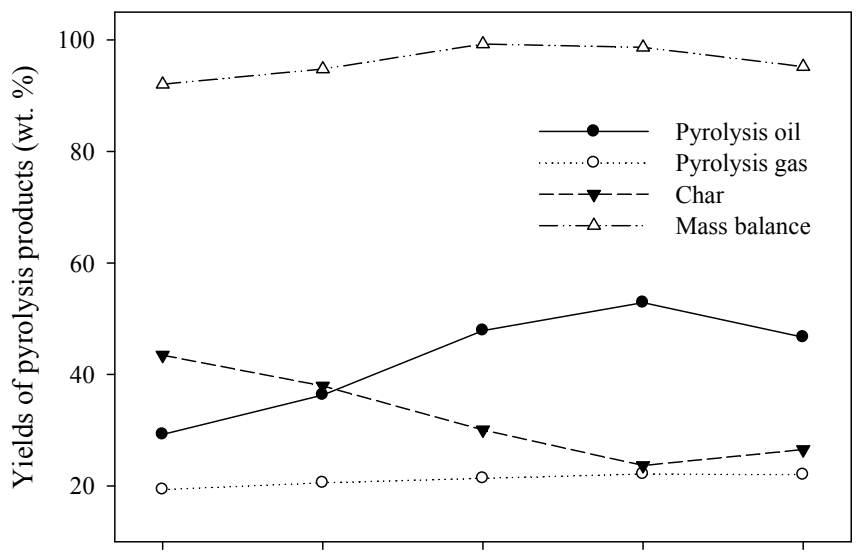

No catalyst Fe/A10.05-Bent Fe/Al0.1-Bent Fe/A10.5-Bent Fe/All.0-Bent

The reaction systems without or with various catalysts

Fig. 5. The yield of pyrolysis oil from oily sludge in the absence of catalyst and presence of various catalysts (2.0 wt\%) 
It is noted that the pillared clay of $\mathrm{Fe} / \mathrm{Al} 0.5$-Bent exhibits the highest catalysis activity among the tested additives, which might be due to its greater Lewis acidity than other catalysts. As reported previously, the reactions, such as transformation of fatty acids to lighter hydrocarbons, decarboxylation and $\mathrm{C}-\mathrm{C}$ cleavage, are considered as the most important processes for pyrolysis of oily sludge (Bridgwater et al. 1999). Those cracking reactions can be promoted by the Lewis acid sites (Almon et al. 1977). Thus, the related catalytic activity of $\mathrm{Fe} / \mathrm{Al}$-pillared bentonites is ascribed to the acid center which is beneficial to the pyrolysis reaction of oily sludge.

\section{Liquid product analysis}

The composition of the recovery oil samples obtained from the pyrolysis process in the presence of pillared bentonites was identified by GC-MS analysis, and the pyrolysis oil without catalyst addition was employed for comparison. Fig. 6 displays the GC-MS chromatograms of the recovery oil, and the peaks were identified by comparing with data in the NIST library. The aliphatic fractions consisting of $n$-alkanes, alkenes and branched hydrocarbons are listed in Table 1 . Note that the recovered oil samples have very complex compositions with carbon number ranging from $\mathrm{C} 8 \mathrm{-C} 31$. However, the proportions of hydrocarbon fractions in the pyrolysis oils are dramatically changed with the addition of pillared bentonite.

Compared with pyrolysis oil without catalyst addition, the proportion of $\mathrm{C} 20-\mathrm{C} 31$ is reduced and accompanied by increasing content of C11-C20 in recovery oil in the presence of pillared bentonite (as shown in Fig. 6). Hydrocarbon fractions of C12-C16, such as dodecane, tridecane, tetradecane, cyclotetradecane, pentadecane, hexadecane, in pyrolysis oil with pillared bentonite are greater than those without addictive (Table 1). Meanwhile, the alkenes compounds and naphthalene compounds with C13-C20, such as 1,6,7-trimethyl-naphthalene, 1,4,6-trimethyl-naphthalene, 2-methyl-pentadecane, 1-hexadecene, 1-octadecene, 2-methyl-Heptadecane, and 1-eicosene are also detected in pyrolysis oil in the presence of catalyst. The formation of those compounds might be due to the effect of catalytic pyrolysis in the presence of Fe/Al-pillared bentonite. On the other hand, the hydrocarbon fractions of C18-C31, such as nonadecane, eicosane, heneicosane, heneicosane, docosane, tricosane, tetracosane, heptacosane, nonacosane, and hentriacontane, in pyrolysis oil in the presence of catalyst are lower than those in the absence of catalyst. The result indicates that $\mathrm{C} 18-\mathrm{C} 31$ hydrocarbons have a preference for the degradation into some light oil compounds, leading to the relative enrichment $\mathrm{C} 11-\mathrm{C} 20$ fractions in the recovered oil. In addition, the decrease of some C9-C13 fractions might be due to their transformation into low-molecular-weight organic gases such as $\mathrm{C}_{\mathrm{x}} \mathrm{H}_{\mathrm{y}}$, which have escaped by the evaporation of solvent during the fractionation of oils.

Aliphatics are important for the application of oil as fuel. As a high quality fuel, the hydrocarbon molecules should be of straight chain, possessing high heating value and low viscosity (Tamer et al. 2006). As shown in Table 1, the pyrolysis oil in

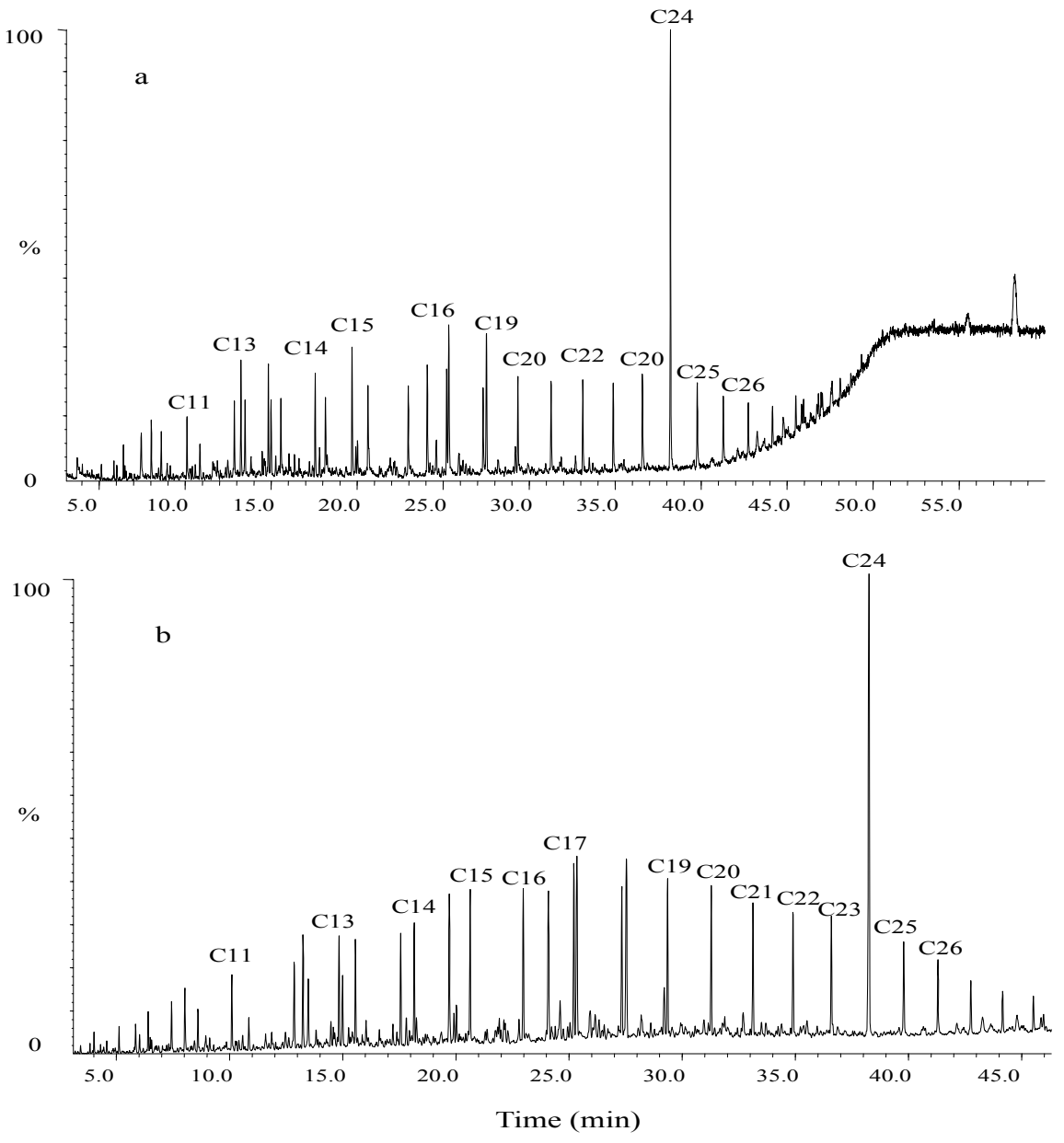

Fig. 6. GC-MS of the pyrolysis oil produced (a) without and (b) with Fe/Al pillared bentonite (Fe/Al 0.5- Bent) addition under $\mathrm{N} 2$ atmosphere 
the presence of catalyst has higher $\mathrm{C} 11-\mathrm{C} 16$ aliphatic contents with less heterochain compounds compared with those in the absence of catalyst, which is in favor of its application as fuel. As reported previously, the oxygenated aromatics of sewage sludge could be transformed into aliphatics during the low temperature pyrolysis, and the distillation characteristic of those liquid products is close to diesel oil (Tamer et al. 2006, Shen et al. 2005). Overall, pyrolysis has the advantages of producing a liquid product that can be easily stored and transported, and the recovered oil was proven to be comparable to low-grade petroleum distillates from commercial refineries and could be directly used in diesel fuel led engines (Czernik et al. 2004, Chiaramonti et al. 2007).

\section{Gas and solid products in pyrolysis process}

The major gaseous products from pyrolysis include $\mathrm{CO}_{2}, \mathrm{CO}$, and hydrocarbons such as $\mathrm{CH}_{4}$ (Wang et al. 2007, Werle 2012). The formation of gas products as function of reaction time under the same pyrolysis conditions in the presence and absence of catalyst were analyzed. As shown in Fig. 7, the content of $\mathrm{CO}$ and $\mathrm{CH}_{4}$ in pyrolysis gas in the presence of catalyst is slightly greater than those in the absence of catalyst, especially, in the early stage of pyrolysis. The formation of $\mathrm{CO}$ and $\mathrm{CH}_{4}$ is mainly due to the decomposition of long chain compounds. As reported previously, the $-\mathrm{CH}_{3}$ side chain of the hydrocarbons in the oil sludge is mainly responsible for the formation of $\mathrm{CH}_{4}$ (Liu et al. 2009). The presence of catalyst is favorable to the formation of free radicals in pyrolysis process, thus enhancing the cleaving of hydrocarbons (Beis et al. 2002). Fe and Al based catalysts have been proven to present great activities towards the decomposition of organic matters in oil sludge, and thus remarkably increasing the oil yield and pyrolytic gas, especially promoting the decomposition of organic matters to produce organic volatiles (Kandiyoti et al. 2008).

Except for liquid and gaseous products, solid residue is considered as one of the main byproducts during the pyrolysis process. Due to its potential toxicity and high calorific value, several methods, such as incineration, landfilling, and utilization as adsorbents, have been developed to treat or reuse it (da Silva et al. 2012). Incineration is an effective approach for treating oil sludge residue. The calorific value is an important parameter in the evaluation of feasibility of sludge residue incineration. In the present study, calorific values of the sludge residue after pyrolysis in the absence and presence of catalyst are 10343.3 and $9359.2 \mathrm{~kJ} \mathrm{~kg}^{-1}$ respectively. It can be found that the sludge residue has relatively high calorific values, which is enough for incineration treatment (Yan et al. 2012). Thus the solid residue from pyrolysis of oily sludge can be used as fuel in incineration process.

\section{Conclusions}

Pyrolysis is an alternative technology for oil sludge treatment. The presence of Fe/Al-pillared bentonites promotes the oil yield. Especially, in the case of Fe/Al 0.5-Bent, the oil yield increases from $29.23 \%$ to $52.46 \%$ compared with the sample without catalyst addition. The enhancement of oil recovery can be attributed to the properties of $\mathrm{Fe} / \mathrm{Al}$ pillaring in bentonite, which produces a porous material with a high surface area and the Lewis acid center in the inner surface conducive to decomposition and cracking of oil molecules organic matters in oily sludge. Moreover, the addition of catalyst also reduces the yield of char and promotes the formation of $\mathrm{CH}_{4}$ and $\mathrm{CO}$, and improves the quality of pyrolysis oil. The recovery oil in the presence of catalyst has higher $\mathrm{C} 13-\mathrm{C} 19$ aliphatic contents with less heterochain compounds compared to the sample without additives, which is in favor of its application as fuel, e.g., diesel oil. The obtained results imply that Fe/Al-pillared bentonite as additive holds great potential in the industrial pyrolysis treatment of oily sludge.

\section{Acknowledgement}

Financial support by the West Light Foundation of Chinese Academy of Sciences (2015-XBQN-A-03), the Xinjiang Program of Introducing High-Level Talents (Y539031601), the Natural Science Foundation of China (Grants No. 41571446), West Light Foundation of The Chinese Academy of Sciences, and the CAS Youth Innovation Promotion Association (2016380) are gratefully acknowledged.

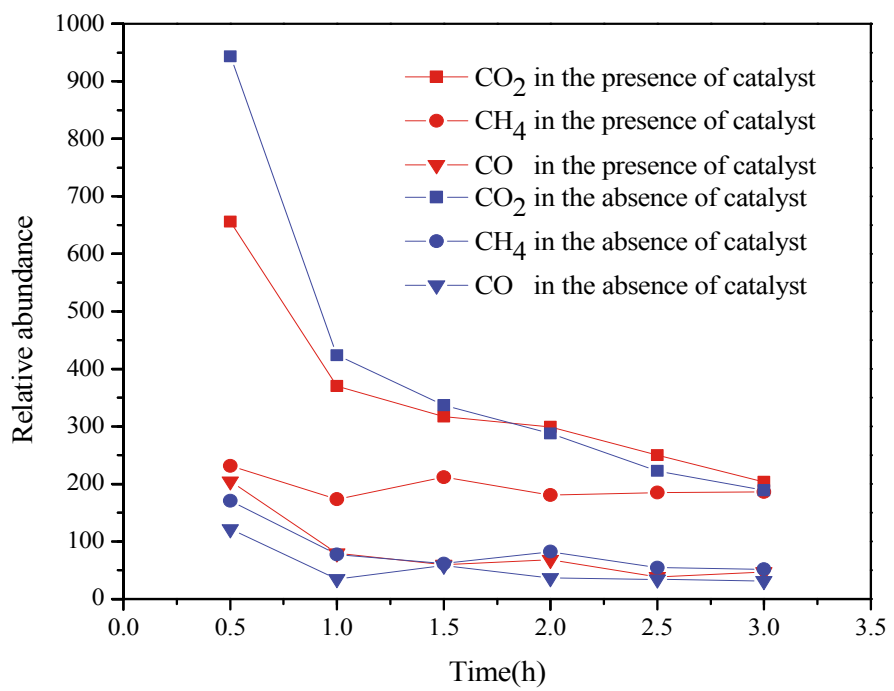

Fig. 7. GC analysis of pyrolysis gas in the presence and absence of catalyst (Fe/Al 0.5- Bent) during pyrolysis process 


\section{References}

Albright, L.F., Crynes, B.L. \& Corcora, W.H. (1983). Pyrolysis: Theory and Industrial Practice, Academic Press New York Ny. (https://www.osti.gov/scitech/biblio/6355324(02.06.2017)).

Almon, W. \& Johns, W. (1977). Petroleum forming reactions: the mechanism and rate of clay catalyzed fatty acid decarboxylation, Enadimsa: Madrid, pp. 157-172.

Baik, O.D. \& Mittal, G.S. (2002). Heat transfer coefficients during deep-fat frying of a tofu disc, Transactions of the ASAE, 45, pp. 1493-1538.

Beis, H., Onay, O. \& Kockar, O.M. (2002). Fixed-bed pyrolysis of safflower seed: influence of pyrolysis parameters on product yields and compositions, Renew Energy, 26(1), pp. 21-32.

Berend, I., Cases, J.M., Francois, M., Uriot, J.P. \& Michot, L. (1995). Mechanism of adsorption and desorption of water vapor by homoionic montmorillonites; 2, The Li (super ${ }^{+}$), Na (super ${ }^{+}$), $\mathrm{K}\left(\right.$ super $\left.^{+}\right), \mathrm{Rb}\left(\right.$ super $\left.^{+}\right)$and $\mathrm{Cs}\left(\right.$ super $\left.^{+}\right)$-exchanged forms, Clays and Clay Minerals, 43, pp. 324-336.

Bridgwater, A., Meier, D. \& Radlein, D. (1999). An overview of fast pyrolysis of biomass, Organic Geochemistry, 30, pp. 1479-1493.

Chen, K., Wang, G.H., Li, W.B., Wan, D., Hu, Q., Lu, L.L., Wei, X.B. \& Cheng, Z.Z. (2015). Synthesis of magnetically modified Fe-Al pillared bentonite and heterogeneous Fenton-like degradation of Orange II, Journal of Wuhan University of Technology-Mater. Sci. Ed., 30(2), pp. 302-306.

Chiaramonti, D., Oasmaa, A. \& Solantausta, Y. (2007). Power generation using fast pyrolysis liquids from biomass, Renewable \& Sustainable Energy Reviews, 11, pp. 1056-1086.

Ciajolo, A. \& Barbella, R. (1984). Pyrolysis and oxidation of heavy fuel oils and their fractions in a thermogravimetric apparatus, Fuel, 63, pp. 657-661.

Czernik, S. \& Bridgwater, A. V. (2004). Overview of applications of biomass fast pyrolysis oil, Fuel, 18, pp. 590-598.

Da Silva, L.J., Alves, F.C. \& Francfia, F.P. (2012). A review of the technological solutions for the treatment of oily sludges from petroleum refineries, Waste Management \& Research, 30 (10), pp. $1-15$.

European Commission DG Environment-B/2, Disposal and recycling routes for sewage sludge scientific and technical sub-component report, 23/10/2001.

Fakhru'l-Razi, A., Pendashteh, A., Abdullah, L.C., Biak, D.R.A., Madaeni, S.S. \& Abidin, Z.Z. (2009). Review of technologies for oil and gas produced water treatment, Journal of Hazardous Materials, 170, pp. 530-551.

Ge, Z.G., Li, D.Y. \& Pinnavaia, T.J. (1994). Preparation of aluminapillared montmorillonites with high thermal stability, regular microporosity and Lewis/Brönsted acidity, Microporous Materials, 3, pp. 165-175.

Kandiyoti, R., Herod, A.A. \& Bartle, K.D. (2006). Solid fuels and heavy hydrocarbon liquids: Thermal characterization and analysis, Elsevier: London, ISBN: 978008044864.

Kök, M.V. \& Karacan, O. (1998). Pyrolysis analysis and kinetics of crude oils, Journal of Thermal Analysis and Calorimetry, 52, pp. 781-788.

Li, C.T., Lee, W.J., Mi, H.H. \& Su, C.C. (1995). PAH emission from the incineration of waste oily sludge and PE plastic mixtures, Science of the Total Environment, 170, pp. 171-183.

Liu, J.G., Jiang, X.M., Zhou, L.S. \& Han, X.X. (2009). Pyrolysis treatment of oil sludge and model-free kinetics analysis, Journal of Hazardous Materials, 161, pp. 1208-1215.

Maksimova, N.I. \& Krivoruchko, O.P. (1999). Study of thermocatalytic decomposition of polyethylene and polyvinyl alcohol in the presence of an unsteady-state Fe-containing catalyst, Chemical Engineering Science, 54 (20), pp. 4351-4357.

Mater, L., Sperb, R.M., Madureira, L., Rosin, A. \& Correa, A. (2006). Proposal of a sequential treatment methodology for the safe reuse of oil sludge-contaminated soil, Journal of Hazardous Materials, 136, pp. 967-971.
Pánek, P. \& Kostura, B. (2014). Pyrolysis of oil sludge with calcium-containing additive, Journal of Analytical \& Applied Pyrolysis, 108, pp. 274-283.

Saha, B., Maiti, A.K. \& Ghoshal, A.K. (2006). Model-free method for isothermal and non-isothermal decomposition kinetics analysis of PET sample, Thermochimica Acta, 444, pp. 46-52.

Shen, L. \& Zhang, D.K. (2002). An experimental study of oil recovery from sewage sludge by low-temperature pyrolysis in a fluidised-bed, Fuel, 82, pp. 465-472.

Shen, L. \& Zhang, D.K. (2005). Low-temperature pyrolysis of sewage sludge and putrescible garbage for fuel oil production, Fuel, 84, pp. 809-815.

Shie, J.L., Chang, C.Y., Lin, J.P., Wu, C.H. \& Lee, D.J. (2000). Resources recovery of oil sludge by pyrolysis: kinetics study, Journal of Chemical Technology \& Biotechnology, 75, pp. 443-450.

Shie, J.L., Chang, C.Y. \& Lin, J.P. (2000). Major Products obtained from the pyrolysis of oil sludge, Energy \& Fuels, 14, pp. 1176-1183

Shie, J.L., Lin, J.P., Chang, C.Y., Lee, D.J. \& Wu, C.H. (2003). Pyrolysis of oil sludge with additives of sodium and potassium compounds, Resources Conservation \& Recycling, 39, pp. 51-64.

Shie, J.L., Chang, C.Y., Lee, D.J. \& Wu, C.H. (2002). Use of inexpensive additives in pyrolysis of oil sludge, Energy \& Fuels, 16, pp. 102-108.

Shie, J.L., Lin, J.P., Chang, C.Y., Lee, D.J. \& Wu, C.H. (2002). Use of calcium compounds as additives for oil sludge pyrolysis, Journal of the Chinese Institute of Environmental Engerineering (Taiwan), 12(4), pp. 363-371.

Shie, J.L., Lin, J.P., Chang, C.Y., Shih, S.M., Lee, D.J. \& Wu, C.H. (2004). Pyrolysis of oil sludge with additives of catalytic wastes, Journal of Analytical \& Applied Pyrolysis, 71, pp. 695-707.

Sing, K.S.W., Everett, D.H., Haul, R.A.W., Moscou, L. \& Pierotti, R.A. (1958). Reporting physisorption data for gas/solid systems with special reference to the determination of surface area and porosity, Pure \& Applied Chemistry, 57, pp. 603-619.

Tamer, K., Jale, Y.K., Mithat, Y. \& Henning, B. (2006). Characterisation of products from pyrolysis of waste sludges, Fuel, 85, pp. $1498-1508$.

Tyagi, B., Chudasama, C.D. \& Jasra, R.V. (2006). Characterization of surface acidity of an acid montmorillonite activated with hydrothermal, ultrasonic and microwave techniques, Applied Clay Science, 31, pp. 16-28.

Ubani O., Atagana, H.I., Thantsha, M.S. \& Rasheed, A. (2016). Identification and characterisation of oil sludge degrading bacteria isolated from compost, Archives of Environmental Protection, 42(2), pp. 67-77.

Wang, Z.Q., Guo, Q.J. \& Liu, X. (2007). Low temperature pyrolysis characteristics of oil sludge under various heating conditions, Energy Fuels, 21, pp. 957-962.

Wang, Z.Q., Guo, Q.G., Liu, X.M. \& Cao, C.Q. (2007). Low Temperature pyrolysis characteristics of oil sludge under various heating conditions, Energy \& Fuels, 21, pp. 957-962.

Wei, Z.B, Michael Moldowan, J., Dahl, J., Goldstein, T.P. \& Jarvie, D.M. (2006). The catalytic effects of minerals on the formation of diamondoids from kerogen macromolecules, Organic Geochemistry, 37(11), pp. 1421-1436.

Werle, S. (2012). Possibility of NOx emission reduction from combustion process using sewage sludge gasification gas as an additional fuel, Archives of Environmental Protection, 38(3), pp. 81-89.

Wiśniewski, D., Gołaszewski, J. \& Białowiec, A. (2015). The pyrolysis and gasification of digestate from agricultural biogas plant, Archives of Environmental Protection, 41(3), pp. 70-75.

Yan, P., Lu, M., Yang, Q., Zhang, H.L., Zhang, Z.Z. \& Chen, R. (2012). Oil recovery from refinery oily sludge using a rhamnolipid biosurfactant-producing Pseudomonas, Bioresource Technology, 116, pp. 24-28. 